\title{
(t)
}

\section{A MEDIAÇÃO DA ARTE NO TRABALHO EDUCATIVO DO SERVIÇO SOCIAL PARA A EMANCIPAÇÃO HUMANA}

\author{
The mediation of art in the educative work of the Social Service to \\ human emancipation
}

\section{Isabel Cristina Chaves Lopes ${ }^{1}$}

\begin{abstract}
RESUMO
O presente trabalho tem por objetivo apresentar, em nível de reflexões, questões relativas a articulação entre o debate do trabalho profissional do assistente social e estudos acerca do caráter político da arte a partir do pensamento marxiano. Tal articulação é compreendida e apresentada, enquanto uma mediação política, que possibilita contribuições ao desenvolvimento de uma cultura para a emancipação humana. Entende-se também que para tal processo o conceito de emancipação política precisa ser considerado, visando converter os movimentos capazes de realização nestes marcos, em estratégias de conduções à emancipação humana. Para tal conquista, no entanto, temos por certo ser imprescindível a interferência no universo dos valores sintonizados com os dos movimentos sociais e com experiências teórico-práticas que favoreçam processos de suspensões cotidianas.
\end{abstract}

PALAVRAS-CHAVE

Arte. Mediação. Serviço Social. Emancipação Humana.

\section{ABSTRACT}

This paper aims to present, at the level of reflections, questions related to the articulation between the professional work debate of the social worker and the studies about the political character of art from the Marxian thought. Such articulation is understood and presented, as a political mediation,

\footnotetext{
${ }^{1}$ Assistente Social. Doutora em Serviço Social. Docente Adjunto IV do Departamento de Serviço Social de Campos da Universidade Federal Fluminense (UFF, Rio de Janeiro, Brasil). Rua José do Patrocínio, n 71, Centro, Campos, RJ, CEP.: 28010-385. E-mail: <icrislopes@vm.uff.br>.
} 
that enables contributions to the development of a culture for human emancipation. It is also understood that, for such a process of the concept of political emancipation needs to be considered, with the aim of converting the movements that are capable of accomplishment in these milestones, in strategies of conducts to human emancipation. For this achievement, however, we must, of course, be indispensable to interfere in the universe of values in tune with those of social movements and with theoretical-practical experiences that favors processes of daily suspensions.

\section{KEYWORDS}

Social Services, Dimension Technical Operations, Professional Work, Professional qualification in Social Work.

Submetido em: 15/2/2017

Aceito em: 19/7/2017

\section{INTRODUÇÃO}

Falar de exercício ético-profissional do Serviço Social envolve, antes de tudo, recorrência à análise do contexto político ${ }^{2}$ no qual tal exercício realiza-se. Tal recorrência deve efetivar-se procurando avaliar a necessidade ou não de enfrentamentos a elementos que determinam a forma e o conteúdo deste exercício, que estabelecem entre si uma relação de unidade dialética. Também é necessária a identificação de mediações já existentes capazes de qualificar positivamente tal exercício, portanto necessárias ao mesmo, assim como as mediações necessárias ainda não existentes que insinuam capacidade para o alcance de tal intento. Ao nos referirmos à qualificação de positivo ao exercício profissional, aludimos a um trabalho que prime pelos princípios do Código de Ética Profissional do Assistente Social, como um componente imprescindível à materialização das competências ética, política, teórica e técnica deste trabalho. Isto porque a este procedimento, que podemos denominar racionalização do trabalho do assistente social, precisa ser incorporada a compreensão do sentido do fazer profissional, da função social desta profissão, ou nos dizeres de Guerra (1995), da sua instrumentalidade dentro do sistema capitalista. Para tanto, o exercício profissional deve ser considerado a partir do resgate das atribuições da profissão, presentes em seu Projeto Ético Político Profissional (PEP) ${ }^{3}$ e

\footnotetext{
${ }^{2}$ Que não é compreendido aqui enquanto desvinculado do fator econômico.

3 Onde se encontra a projeção de sociedade que deve orientar as ações do pro-
} 
dos recursos de que dispõe o profissional ou pode passar a dispor, que acionados, favoreçam a consecução dos objetivos específicos e gerais de seu trabalho.

Tais requisitos podem favorecer a problematização por parte do Serviço Social das demandas que lhes são apresentadas e da forma como são atendidas, em uma perspectiva de totalidade. Portanto, em uma perspectiva que trate com as duas dimensões do conhecimento exploradas por Marx, a ontológica e a gnosiológica. Fazê-lo nos propicia entender a

[...] razão de ser e a razão de conhecer da profissão

[...] na dialética contingência e necessidade, [...] [dissolvendo] o caráter absoluto da causalidade posta na razão de ser do Serviço Social, [inscrevendo tal fazer] no horizonte das possibilidades (GUERRA, 1995, p. 202).

A razão de ser da profissão para o capital não é a mesma que pode e deve ser para os interesses emancipatórios do trabalho. Para estes, esta a razão de ser deve estar vinculada ao seu processo de conquista de liberdades, iniciada pela via da afirmação de seus direitos. Portanto, não se pode perder de vista que, sendo as expressões da questão social o objeto de ação do trabalho do assistente social, a partir dos princípios defendidos pelo Projeto Ético Político do Serviço Social, a preocupação maior e final do assistente social deva residir na defesa dos direitos e na afirmação dos indivíduos enquanto expressão radicalizada das condições dos mesmos enquanto seres sociais. Concordamos com lamamoto (2011, p. 36), quando afirma que repor "[...] o humanismo marxista no centro da análise é condição necessária para fazer emergir o indivíduo social, como sujeito criativo vivo, presente no pensamento de Marx."

Nosso ponto de partida para as análises e reflexões neste texto, portanto, é o resgate, na ação profissional do assistente social, da centralidade do indivíduo enquanto expressão do ser social, cuja base fundante, a partir da ontologia social de Marx é o trabalho, e que está inserido, em tratando-se de capitalismo, em uma das classes principais em antagonismo nas lutas nele travadas. Tal resgate tem o

fissional, através, por exemplo, da definição de suas atribuições enquanto tal. 
sentido político de, entre outros, gerar contribuições a formas contra hegemônicas ${ }^{4}$ aosefeitosdacriseeconômicamundial onde "[...][com] o recuo da organização, da consciência de classe e o desaparecimento do espectro do comunismo, o capital voltou à sua 'maneira normal' de maximizar a exploração e lucro" (PETRAS, 2007, p. 243). Com isto

A concentração e centralização de capital em escala global e o desenvolvimento de novas tecnologias são acompanhados pelo ressurgimento de modos de produção pré-capitalistas baseados na exploração extensiva do trabalho (PETRAS, 2007, p. 250).

A crise econômica que assola o mundo capitalista desde os anos 70 do século passado, tem acentuado a falta de sentido humanizado nas relações sociais. Isto basicamente em função das diversas configurações de alienação geradas pela forma de reprodução da mercadoria, que no modelo atual de acumulação de mais-valia têm "[...] transformado as relações de trabalho, o processo de trabalho e a distribuição da renda no interior do quadro e dos parâmetros definidos pelas formas dominantes do capital corporativo" (PETRAS, 2007, p. 252).

O avanço do capitalismo em sua forma mundializada5, quer dizer, na sua fase de acumulação flexível e reestruturação produtiva, caracteriza-se, entre outros elementos, pela efemeridade e instabilidade como afirma Harvey (2000), aprofundando o fosso entre ricos e pobres, aprofundando o racismo e a xenofobia, assim como a crise ecológica do globo (NETTO, 2000).

A transformação social que daí advém, vem acompanhada da "[...] mobilização de todos os artifícios de indução de necessidades" (HARVEY, 2000, p.148), onde o consumo indiscriminado apresenta-se como característica destafase, assim comoanecessidade doimediato, do fragmentário, do individualismo, onde a aparência resumiria

\footnotetext{
${ }^{4}$ A direção hegemônica, a partir de Gramsci, deve exercer-se no campo das ideias e da cultura, manifestando a capacidade de conquistar consenso e formar uma base social.

${ }^{5}$ Expressão utilizada por François Chesnais (1996) para enfatizar e analisar a vinculação da mundialização dos mercados financeiros à privatização dos Estados Nacionais, aumento do desemprego e do empobrecimento mundiais da classe trabalhadora.
} 
todas as verdades, visto que na "[...] 'sensibilidade consumidora' [...], a própria distinção entre realidade e signos se esfuma: numa semiologização do real, o signo é o real” (NETTO, 2000, p. 97).

A reestruturação da produção nesta fase do capitalismo "[...] compatibiliza mudanças institucionais e organizacionais nas relações de produção e de trabalho, bem como redefinição de papéis dos estados nacionais e das instituições financeiras" (NETTO, 2000, p. 97). No que tange ao trabalhador, acarreta prejuízos de diversas ordens, como por exemplo, à sua subjetividade ${ }^{6}$ e seu potencial crítico de negação do sistema de exploração ao qual está submetido.

Neste âmbito, o capital reinventa novas formas de organização e gerenciamento do processo de trabalho para racionalizar e potencializar o consumo produtivo da força de trabalho. [...] as empresas buscam um trabalhador flexível, que possa executar diferentes tarefas. [...] a reestruturação produtiva, com seus novos métodos e técnicas [...] recompõe a unidade das diferentes fases do processo de trabalho, recriando um novo tipo de trabalhador coletivo combinado (TEIXEIRA, 2000, p. 219).

Na concepção de Antunes (1999)

[...] a diminuição da divisão rígida entre elaboração e execução torna mais presente a dimensão ativa do trabalho, uma vez que a sua esfera de subjetividade é incitada para o envolvimento com o projeto da empresa e o seu consequente processo de criação de valores.

[...] Trata-se, entretanto, da construção de uma subjetividade inautêntica [...], pois a dimensão de subjetividade presente nesse processo de trabalho está tolhida e voltada para a valorização e auto reprodução do capital, para 'a qualidade', para o atendimento ao consumidor, entre tantas formas de representação ideológica, valorativa e simbólica que o capital introduz no interior do processo produtivo (ANTUNES, 1999, p. 128).

6"[...] a subjetividade é um momento constitutivo das práxis social, numa inter-relaçãoo ineliminável entre a esfera do sujeito e a atividade do trabalho. É ontologicamente inconcebível, nessa formulação, separar a esfera da subjetividade do universo laborativo [...]" (ANTUNES, 1999, p.161) 
Diante do exposto, fica óbvio que este quadro torna mais complexas as condições de formação da consciência social do operário, o que demanda um caráter de ação conjunta no desenvolvimento de subjetividades sintonizadas com o desejo de uma utopia historicamente realizável. Sobre utopia entendemos

[...] a formação de uma cultura, concepção de mundo e de ética nova que envolva um maior número de pessoas na sociedade e se alarguem de tal maneira que 'se tornem uma norma ativa de conduta' (SEMERARO, 1999, p.166).

O aspecto cultural, portanto, compreendido basicamente como expressão do modo de produção que se desenvolve no cotidiano, ocupa caráter de preponderância nos processos políticos de conservação ou superação de questões da ordem estabelecida, não prescindindo de sujeitos sociais, organizados em suas capacidades de enfrentamentos de situações que avaliem exploradoras e mutiladoras da condição de humano genérico. Sobre este, como uma qualidade inexorável do ser social, expressa-se em níveis que as condições históricas permitem. Ou seja, só se materializa e aprofunda através da afirmação de particularidades e singularidades, a partir da qual a condição de indivíduo emerge e pode dar contribuição a tal configuração e aprofundamento.

Tal contribuição demanda uma apreensão do cotidiano como um espaço caracterizado pela imediaticidade, heterogeneidade e superficialidade, mediadoras dos processos de alienação, mas também como "[...] um campo de disputa entre alienação e desalienação" (ANTUNES, 1999, p.160), onde desconstruções e reconstruções são realizadas. Sendo que, para Gramsci apud Maar (2000, p.123), toda

[...] 'desconstrução', [...], deve ser acompanhada por uma profunda atividade de reconstrução social que amplie os espaços da participação coletiva, da liberdade, da justiça e que seja política e economicamente uma conquista a favor das classes populares (GRAMSCl apud MAAR, 2000, p. 123).

Objetivamos que tais questões, mesmo apresentadas de forma breve, apontem para a importância da atenção ao componente 
cultural presente nos contextos de trabalho do assistente social, quer dizer, como a esfera onde valores e formas de ser e de pensar podem ser postos em xeque e serem envolvidos em processos de desconfiguração. Resgatar a dimensão pedagógica do trabalho profissional na direção deste compromisso é de crucial importância posto possibilitar o desenvolvimento da compreensão de suas formas de intervenção como realização de cultura.

Destacamos a importância da recorrência aos fundamentos teóricos e metodológicos do Serviço Social para uma clara compreensão do exercício profissional como expressão de um feixe de mediações, onde destacam-se educação e trabalho, como formas de cultura, que enquanto tais podem ser articulados a arte como práxis. Sobre esta articulação, enfatizamos em nossos estudos sua capacidade de orientação reflexiva e prática a um processo de trabalho que deseje se confrontar com formas estruturais de alienação. No entanto, em termos profissionais, há que se cuidar das ciladas do idealismo e do romantismo, sustentando um ideal de trabalho em bases concretas, mas compreendido da maneira mais ampla e enriquecedora possível.

\section{ATENÇÃO ÀS MEDIAÇÕES NECESSÁRIAS}

O feixe de articulação entre as mediações teóricas e práticas da arte, do trabalho e da educação, pode produzir uma mediação com poder de intervenção junto ao exercício da reflexão profunda, necessária ao aprendizado para a criatividade, elemento imprescindível para a construção de possibilidades dirigidas à emancipação humana. Esta é compreendida, apesar de nossa atenção à questão dos valores que devem se fazer presentes em processos educativos mediadores do desenvolvimento de uma consciência social totalizadora, como uma emancipação "[...] que não se restringe à esfera política, já que pretende liberar também os sentidos do homem da deformação e do dilaceramento a ele impostos" (FREDERICO, 2013, p. 55).

Pensar a mediação da arte dentro deste processo pressupõe a compreensão da necessidade de mediações das qualidades que lhe são essencialmente características, mas que podem se desenvolver ou não, como a constituição de individualidades autênticas, o estímulo à autonomia, o exercício da criatividade, 
entre outros. Tal procedimento torna-se necessário como forma de justifica-la em uma discussão de âmbito político, de natureza radical, como a discussão da emancipação humana. Necessário também se faz não desenvolver as análises de forma idealista, a partir das quais a práxis artística não teria muito como expressar sua capacidade interventiva de contribuição a processos de transformação da realidade social.

Partimos do princípio de que é através do conhecimento das contradiçõese das diversidades socioculturais, presentesnos modos de vida dos indivíduos, assim como das análises e compreensão destas, com o olhar dirigido a interesses emancipatórios, que podemos nos educar para entender o mundo de forma mais sensível, justa e livre, para com isto, desenvolvermos melhor nossa capacidade de educar para um mundo mais humano.

Há contradições na história da vida em sociedade que não são muito visibilizadas por alguns processos educativos, sejam formais ou não. O conhecimento delas, no entanto, explicaria níveis de exploração e fragmentação a que são submetidos trabalhadores em suas relações imediatas e mediatas com o mundo do trabalho. Deste modo, é importante que os processos educativos observem a necessidade de identificar e trabalhar com recursos que propiciem a elucidação e o conhecimento destas contradições, para assim transformarem-se em mediações políticas voltadas a uma forma de educação com potencial emancipatório ${ }^{8}$.

Sob esta perspectiva, é imperativo incorporar a tais reflexões e estudos o projeto de materialização da emancipação política,

\footnotetext{
7 "Não se trata, aqui, de reduzir a pluralidade das contradições e dos conflitos a uma linha de frente prioritária ou exclusiva, nem de opor uma totalidade abstrata e fetichizada à inquietude, pós-moderna, mas de admitir que a destotalização reivindicada pelas micronarrativas, pela micro história ou pela microssociologia pressupõe a totalização concreta à qual se opõe. Se ela não se baseasse mais em uma convergência tendencial real, da qual o próprio capital é o agente impessoal sob as formas perversas da globalização mercantil, a unificação puramente subjetiva das lutas dependeria de uma vontade arbitrária, em outras palavras: de um voluntarismo ético" (BENSAID, 2008, p. 52).

8 "O que precisa ser confrontado e alterado fundamentalmente é todo sistema de internalização, com todas as suas dimensões, visíveis e ocultas. Romper com a lógica do capital na área da educação equivale, portanto, a substituir as formas onipresentes e profundamente enraizadas de internalização mistificadora por uma alternativa concreta abrangente ¿" (MÉSZÁROS, 2006, p. 47).
} 
enquanto mediação possível à conquista da emancipação humana no processar da história. Mister ainda se faz destacar que tal consideração não se realiza a partir de uma linha de análise de caráter determinista.

Em tal debate, a perspectiva teórica que resgata o trabalho como mediação central, apresenta-se como um recurso importante, incorporando questões relativas à emancipação política, já que é pelo trabalho, pela forma de produzir que o indivíduo começa a elaborar sua forma de pensar o mundo e de sentido de pertencimento a ele, o que pode ser aprofundado ainda nos limites do capitalismo.

O desenvolvimento do ser social implica o
surgimento de uma racionalidade, de uma
sensibilidade e de uma atividade que, sobre a
base necessária do trabalho, criam objetivações
próprias. [...] O trabalho [...] permanece, ainda,
como o que se poderia chamar de modelo das
objetivações do ser social, uma vez que todas elas
supõem as características constitutivas do trabalho
[...] (NETTO, 2007, p. 43).

Sem desejarmos reduzir o conceito de práxis ao do trabalho, não podemos deixar de considerar que a maneira como o ser humano atua sobre o objeto de realização do trabalho e as interconexões que estabelece e como estabelece em função e a partir desta, traz em si uma dimensão pedagógica, ou seja, de configuração (mesmo que não absoluta) também da sua subjetividade. Isto também não significa reduzir a esfera da educação a esfera do trabalho, posto não deixarmos de considerar as especificidades que cada uma encerra dentro dos contextos sociais. Intencionamos sim apresentar condições para falarmos de forma mais ampla sobre o trabalho como práxis educativa com caráter emancipatório, ao que agregamos a discussão sobre a arte em Marx.

A incorporação destas reflexões em análises em torno da relação entre emancipação humana e emancipação política no trabalho do Serviço Social, deve partir do princípio de que a aplicação do PEP reclama o exercício do pensamento crítico sobre o significado do exercício profissional e sobre o conhecimento do seu objeto, que são as expressões da questão social. 
Para desenvolvermos nossos estudos sobre esta forma de conceber o trabalho profissional, incorporando a questão da diversidade sociocultural, elegemos como base de fundamentação teórica inicial, obras de Antonio Gramsci, em função do autor considerar e enfatizar em seus estudos a cultura como dimensão essencial da vida em sociedade. Em suas teses ele destaca o momento catártico como contribuição da esfera da cultura para o exercício da grande política. A referência ao conceito de catarse, essencial à compreensão de seu pensamento político, é importante ao desenvolvimento de reflexões profundas acerca das possibilidades do trabalho do assistente social comprometido com a afirmação dos princípios do seu PEP, onde compreendemos comportar-se a dialética atuação na defesa da emancipação política com a inspiração valorativa na emancipação humana.

Acionar o potencial político da esfera da cultura demanda interferência no universo das condições de existência objetivas e subjetivas, singulares e universais dos indivíduos sociais e dos sujeitos que constituem a história através de seus laços de convivência, embasados por valores, tradições, crenças, hábitos, entre outros, que em sua universalidade refletem uma condição de classe (THOMPSON apud IAMAMOTO, 2011, p 36).

São nos espaços onde se constituem os laços de convivência e reprodução das relações sociais, que temos condições de identificar as expressões dos processos alienatórios. É neste espaço que podemos alicerçar e acionar mediações que possam agir sobre as manifestações de alienação que caracterizam um modo de vida, onde os atributos do humano-genérico se apresentam de forma fragmentada, superficial e desagregada.

O caráter fragmentado, incoerente dessas concepções de mundo se expressa numa defasagem entre o pensar e o agir. [...]. Outra concepção é afirmada por palavras que a classe acredita seguir, mas que lhe é estranha, porque incorporada de outras classes por razões de submissão e subordinação intelectual. (GRAMSCI apud IAMAMOTO, 2011, p. 36).

Consideramos que uma das mediações capazes de confrontar o contorno dado pelo avanço de contextos culturais que retiram o 
indivíduo de sua condição de inteiramente homem e o fragmentam, possa ser a práxis artística, principalmente em função da sua capacidade de constituição de momentos catárticos ${ }^{9}$ que podem vir a contribuir com saltos qualitativos na direção da materialização de expressões dos princípios da grande política no cotidiano.

Não podemos perder de vista neste processo, que o mesmo não se encerra em ações individuais, a vontade política coletiva e a constituição do sujeito coletivo, são componentes fundamentais na luta por hegemonias, demandando o recurso da ideologia, da educação, da internalização de valores éticos emancipatórios, portanto da teoria, em todas as suas possibilidades de expressão.

A práxis artística pode propiciar a conexão dos indivíduos com sua dimensão essencial, com sua dimensão humana, mas a educação para um sentido mais emancipado da lógica de reificação das relações sociais, ou seja, a educação para a auto identificação dos indivíduos enquanto intelectuais, sujeitos de suas próprias histórias, necessita da contribuição da teoria, que pode ser acessada através da arte. Este teorizar com tal propósito precisa desenvolver-se tendo por base os cotidianos dos mesmos e suas histórias.

Compreendendo o espaço da sua atuação como espaço de realização da cultura e, portanto, do confronto de forças políticas, o trabalho do assistente social pode dar-se a reconhecer a diversidade sociocultural de seus usuários em níveis mais elevados. Este reconhecimento expressa uma forma de compromisso éticopolítico profissional com o qual o assistente social deve orientarse em sua atuação sobre a realidade social, politizando-a na perspectiva da afirmação, em nível de consciência, da dialética singularidade, particularidade e universalidade, como base ontológica de constituição da diversidade social. E isto pode ser realizado com a mediação de um trabalho articulado à mediação da arte apreendida enquanto cultura.

\footnotetext{
${ }_{9}^{9}$ A catarse significa passagem "[...] do particular ao universal, do econômico-corporativo ao ético-político [...]" (COUTINHO, 2001, p. 122), mas também significa "[...] a passagem do 'objetivo ao subjetivo' e da 'necessidade à liberdade' [...]" (COUTINHO, 2001, p. 122). Ocorre de forma gradativa e o ápice de seu alcance é o ponto da afirmação da hegemonia das classes subalternas, é a afirmação do momento ético-político em Gramsci.
} 


\section{O CONCEITO DE ARTE EM MARX}

Em função dos propósitos aos quais nos dispomos no debate sobre a arte, utilizamo-nos do pensamento de Marx. Esta, é abordada pelo mesmo como atividade prática, como práxis, que não está diretamente relacionada ao atendimento das necessidades imediatas de sobrevivência, como é o caso do trabalho. No entanto, ela atende necessidades espirituais de homens e mulheres, acordantes com o nível de desenvolvimento conquistado pelos mesmos no decorrer da história no seu processo de humanização, ou seja, no processo através do qual as determinações naturais, sem deixar de se fazerem presentes, adquirem cada vez menos espaço de determinação nas ações humanas.

Nos Manuscritos Econômicos e Filosóficos de 1844, a arte aparece relacionada ao trabalho como uma extensão do mesmo, mas em relação ao qual mantém relativa autonomia. Também aparece como contraponto ao trabalho estranhado.

As duas atividades - o trabalho e a arte - inserem-se nos processos das objetivações materiais e não materiais que permitiram ao homem separar-se da natureza, transformá-la em seu objeto e moldá-la em conformidade com seus interesses vitais (FREDERICO, 2005, p. 14).

Esta definição de arte desdobra-se do entendimento de estética em Marx, encontrado na sua elaboração de uma ontologia do ser de base materialista, histórica e dialética. A partir de tais concepções, os sentidos humanos também adquirem valor importante e não somente a teoria, no trato com as questões da realidade. No entanto, a utilização dos mesmos é apreendida em Marx, enquanto atividade que se desenvolve no decorrer da história e adquire formas específicas, condizentes com as orientações sociais que recebem e que são determinadas pelas formas com que os modos de produção se estruturam. O que Marx denomina humanização dos sentidos, portanto, segundo ele, depende da educação dos mesmos, visto compreender que a qualidade das expressões estéticas/políticas condiz com o nível e a qualidade da educação que seus sentidos humanos recebem. 


\section{CONSIDERAÇÕES FINAIS}

Consideramos que a arte, concebida a partir de Marx e de sua estética, éuma importante mediaçãono processo de enfrentamento de formas de alienação estruturais no capitalismo, posto ser uma forma de objetivação da dimensão humano-genérica. Expressa, portanto, dimensões ontológicas do trabalho humano, dentre as quais damos especial destaque à criatividade, ou seja, à capacidade do pôr teleológico dos indivíduos. Tal característica, assim como outras, é alienada do homem, a partir de uma pedagogia vivenciada por intermédio de suas experiências junto a processos de trabalho nas fábricas, nas indústrias, nos escritórios, junto a processos de socialização primárias ou não. Partimos da compreensão de que a experiência com a atividade artística pode mediar o resgate da dimensão humano-genérica em níveis mais radicais e, portanto, menos alienados.

A arte como objetivação humana, realizada fora do círculo imediato do trabalho, não envolve neutralidade diante dos fenômenos sociais. Em outras palavras, a subjetividade do sujeito na experiência com a arte, manifesta-se exprimindo suas formas particulares de ler o mundo. Esta manifestação reflete a dialética da essência e do fenômeno, considerada um dos problemas centrais da concepção estética marxista, tratada com o entendimento "[...] de que ambos são igualmente momentos da realidade objetiva, produzidos pela realidade e não pela consciência humana" (LUKÁCS, 2009, p. 104). Tal dialética pode ser objeto de intervenção por parte do Serviço Social, através de um trabalho reflexivo e educativo embasado na teoria crítica, explorando pedagogicamente os processos catárticos vivenciados pela experiência com a arte.

Quando afirmamos, a partir de Gramsci, que os processos catárticos podem ser provocados pela atividade artística, contribuindo para saltos na direção do afastamento da pequena política, rumo à realização da grande política, não consideramos o estabelecimento de uma relação direta entre tal atividade e o nível da ação política a ser conquistado. Também não estamos apresentando a relação com a práxis artística como determinante nas ações de construção da grande política. Pode caber, portanto, 
a arte, servir de mediação ao trabalho do assistente social e este trabalho configurar-se como uma das mediações de um propósito político da magnitude do que Gramsci denomina grande política.

\section{REFERÊNCIAS}

ANTUNES, Ricardo Os sentidos do trabalho: ensaio sobre afirmação e negação do trabalho. São Paulo: Boitempo, 1999.

BENSAID, Daniel. Os irredutíveis: teoremas da resistência para o tempo presente. São Paulo: Boitempo, 2008.

CHESNAIS, François. A mundialização do capital. São Paulo: Xamã, 1996.

COUTINHO, Carlos Nelson. O leitor de Gramsci. Rio de Janeiro: Civilização Brasileira, 2001

FREDERICO, Celso. A arte em Marx: um estudo sobre os manuscritos econômicos filosóficos. Novos Rumos, Marília, ano 20, n. 42, p. 1-24, 2005.

FREDERICO, Celso. Marx: a arte como práxis. In: A ARTE NO MUNDO DOS HOMENS. São Paulo: Expressão Popular, 2013.

GUERRA, Yolanda. A instrumentalidade do Serviço Social. São Paulo: Cortez, 1995.

HARVEY, David. Condição pós-moderna. 9. ed. São Paulo: Loyola, 2000.

IAMAMOTO, Marilda Villela. Trabalho e indivíduo social. 4. ed. São Paulo: Cortez, 2011.

LUKÁCS, György. Arte e Sociedade: escritos estéticos 1932-1967. Rio de Janeiro: UFRJ, 2009.

MAAR, Wolfgang Leo. Formação social em Lukács: dialética de reificação e realização - A perspectiva Marxista como consciência de classe e crítica ontológica. In: BOITO JR, Armando et al . A obra teórica de Marx: atualidade, problemas e interpretações. São Paulo: Xamã, 2000.

MÉSZÁROS, István. A Teoria da Alienação em Marx. São Paulo: Boitempo, 2006. 